\title{
Opinions Regarding the Academy of Managed Care Pharmacy Dossier Submission Guidelines: Results of a Small Survey of Managed Care Organizations and Pharmaceutical Manufacturers
}

\author{
Michael B. Nichol, PhD; Tara K. Knight, PhD; Joshua Epstein, MA; \\ Dennis H. Honda, PharmD; and Roma Tretiak, MHA
}

\begin{abstract}
BACKGROUND: In recent years, there has been more emphasis on determining the total value of a drug product, which includes safety and efficacy information and clinical and economic value relative to other therapies. The Academy of Managed Care Pharmacy (AMCP) Format for Formulary Submissions was intended as a tool to assist health care providers in evaluating and selecting drug products.

OBJECTIVE: The purpose of this research was to gain the perspectives of a sample of managed care organizations (MCOs) and pharmaceutical manufacturers regarding the AMCP Format submission and evaluation process, as well as their comments on possible future direction for these guidelines as an important part of the formulary decision-making process.

METHODS: A random sample of large ( $>1$ million lives) and small $(<1$ million lives) MCOs was generated using telephone numbers from the National Directory of Managed Care Organizations' database. Pharmaceutical manufacturer respondents were identified from the Pharmaceutical Research and Manufacturers of America (PhRMA) Foundation's Health Outcomes Committee. Telephone interviews were conducted by 2 researchers between September 2004 and 0ctober 2005. Respondents from both pharmaceutical manufacturers and MCOs nationwide were familiar with the AMCP dossier preparation and review process, allowing us to compare perspectives from each group. The interview was designed to assess the following key areas: economic models, organizational burden, confidentiality, overall value, and future expectations.
\end{abstract}

RESULTS: Representatives from 20 MCOs and 7 pharmaceutical manufacturers completed the interview; 21 MCO representatives refused to participate, citing company policy. Nearly all (87.5\%) of the MCO personnel contacted reviewed dossiers within their organization. However, MCO respondents indicated that only $40 \%$ of all drugs they reviewed included dossiers from the manufacturers. For drug evaluation at the level of the pharmacy and therapeutics committee, we found that drugs were compared with a variety of products, with 11 respondents reporting comparisons with a placebo, and all respondents reporting a comparison with at least 1 other branded product. On average, $53.5 \%$ of the dossiers MCOs received included budgetimpact models, and $39.3 \%$ included cost-effectiveness analyses (CEAs) or cost-benefit analyses. Of the dossiers with economic models, less than half $(46.2 \%)$ were deemed adequate. Nearly two thirds of MCO respondents reported that they modified the provided model with their own population statistics, as many reported that manufacturers do not make models directly applicable to their health plan population.

The perspectives of the pharmaceutical manufacturers varied dramatically from the MCO respondents with regard to the inclusion of economic models. Five of the 7 respondents indicated that their companies always included an economic model in the submitted dossiers. One respondent indicated that $85 \%$ of company dossiers included models, and another reported that $50 \%$ of dossiers included CEA models. Both MCOs and pharmaceutical manufacturers commented that organizational burden was high, with $70 \%$ of both groups reporting the use of outside consultants to assist in the dossier process.

CONCLUSIONS: Overall, findings for this study suggest that awareness of the AMCP Format is high among MCOs and pharmaceutical manufacturers, but aligning objectives between the 2 organization types is necessary. Conceptually, proving a drug value beyond what the U.S. Food and Drug Administration requires is a reasonable request, something most respondents agreed on. However, less than half of all drugs reviewed had a dossier. In contrast to MCO respondents, pharmaceutical manufacturers appear to have a more positive outlook on the role of the AMCP Format in effectively communicating the value of a new drug product. Further steps need to be taken to improve acceptance and integration of the AMCP Format.

KEYWORDS: AMCP Format, Formulary decision making, Economic models

J Manag Care Pharm. 2007;13(4):360-71

Copyright@ 2007, Academy of Managed Care Pharmacy. All rights reserved.

\section{What is already known about this subject}

- There is little known about how MCOs are receiving and incorporating the drug product dossiers. The experience of $1 \mathrm{MCO}$ showed that it received dossiers in $58 \%$ of the requests, and pharmacoeconomic models were included in $68 \%$ of the dossiers received. However, most dossiers had limited utility because they were not unlocked interactive economic or budget-impact models that permitted use of MCO-specific data. ${ }^{14}$

\section{What this study adds}

- This research provides perspectives on the AMCP Format from both MCO and pharmaceutical manufacturer representatives.

- Less than half of MCO respondents found the pharmacoeconomic (PE) models to be adequate. Two thirds of MCO respondents reported that they used the PE model provided with the dossier to examine the results using data from their own MCOs.

$\mathrm{T}$ he formulary system is intended as a tool to assist health care providers in evaluating and selecting drug products. In the past, the evaluation of drugs by managed care organizations (MCOs) for inclusion on the formulary had a primary focus on safety and efficacy issues and a secondary focus on the overall cost-effectiveness of the product. ${ }^{1}$

There has been a move in recent years to consider all available information in an evidence-based formulary system. In 1994, Regence BlueShield created a set of guidelines for reviewing and 


\section{Opinions Regarding the Academy of Managed Care Pharmacy Dossier Submission Guidelines:}

Results of a Small Survey of Managed Care Organizations and Pharmaceutical Manufacturers

evaluating drug products, ${ }^{2}$ which has since been espoused by the Academy of Managed Care Pharmacy (AMCP) and is currently considered the gold standard for evidence used by MCOs in considering drugs for the formulary. ${ }^{3}$ The main intentions of these guidelines are as follows: (1) decisions regarding a medication's inclusion on a formulary will be based on the overall value that medication brings to a specific population, and (2) the value argument will be based on good scientific evidence, including pharmacoeconomic models as an integral part of formulary review.

The AMCP Format for Formulary Submissions guidelines encourage pharmaceutical manufacturers to submit a structured dossier that includes clinical and economic data from both published and unpublished studies and a disease-based economic model that predicts the product's impact on health outcomes and economic consequences for the specific health plan. Because the guidelines are promoted as a template rather than a mandate, individual MCOs may implement them with modifications to fit their organizations, resulting in a wide variety of outcomes. The Format is now viewed as an industry standard, but little is known about how MCOs and drug companies are receiving and incorporating the guidelines. ${ }^{4-6}$ Of primary concern to many has been the length and preparation involved in the dossier format. Regence BlueShield reported that the time required for its staff members to prepare review summaries for the pharmacy and therapeutics (P\&T) committee decreased over time as they became more experienced with the Format. ${ }^{7}$

To date, few studies have specifically investigated the use of pharmacoeconomic models in formulary decision making. Watkins et al. ${ }^{8}$ used a case-study approach (CORE diabetes model) to show how the use of an economic model can affect formulary decisions. The model demonstrating the effects of exenatide versus comparators on long-term disease burden and costs was included as part of the formulary monograph. The pharmacy staff members of the health plan manipulated the model to project cost outcomes, and in this case, the decision to include the medication on the formulary partially owed to these results.

Earlier, Sullivan et al. reported the results of a roundtable discussion in 2004 involving 12 MCO representatives and pharmacy benefit managers (PBMs). ${ }^{9}$ The main findings from their discussion, which focused on P\&T committee reactions to pharmacoeconomic models, included an emphasis on clinical meaningfulness over statistical significance and on increasing the transparency of models so that P\&T committees could easily adapt the model for their plan population.

Olson et al. conducted a survey of 20 pharmacoeconomic researchers from U.S. pharmaceutical and biotechnology companies to better understand industry views of how MCO decision makers perceive economic models. ${ }^{10}$ Findings suggest that models do affect health policy decisions. Olson et al. also reported important findings regarding intellectual property and confidentiality. Eighty percent of their survey participants would not leave electronic copies of their models with MCOs for a variety of reasons. The $20 \%$ who did provide electronic copies required signed confidentiality agreements, reinforcing the importance of the role of confidentiality guidelines in dossier submissions.

Previous research has shown the growing importance of the role of pharmacoeconomics in drug research and development ${ }^{11}$ as well as in formulary decisions. ${ }^{7,8}$ Little research, however, has investigated the impact of the AMCP dossier in these areas or assessed both pharmaceutical firms and MCO views simultaneously. In the current study, we conducted phone interviews with 35 people from both pharmaceutical manufacturers and MCOs nationwide who are familiar with the AMCP dossier preparation and review. These interviews enabled us to compare perspectives from the respondents of each group. The interviews were designed to assess the following key areas: economic models, organizational burden, confidentiality, overall value, and future expectations. These research topics expanded on those used in previous studies of this nature. ${ }^{10-12}$

This article reports on both the MCOs' and pharmaceutical manufacturers' responses for each key area and provides possible explanations for the discrepancies that were noted. We conclude by commenting on the policy implications of these findings and recommending future action to improve the nature of the AMCP guidelines in the formulary decision-making process.

\section{Methods}

\section{Interview}

A structured interview protocol and questions tailored for MCOs and pharmaceutical companies were developed and pilot tested for use in this project (see Tables 1 and 2). The interview protocol was designed to facilitate information exchange quickly to reduce respondent burden. Each interview lasted approximately 15 minutes. Respondents were asked to recall the past 6 months and comment on the review and formulary decision-making processes. Additionally, respondents were given the opportunity to provide open-ended commentary on the AMCP Format after answering the structured survey questions. Interview content and protocol were reviewed and approved by the appropriate human subjects review committee. Two investigators conducted the interviews using this protocol.

\section{Study Population}

Participants were contacted by phone between September 2004 and October 2005.

MCOs. A random sample of large ( $>1$ million lives) and small ( $<1$ million lives) MCOs was generated using phone numbers from the National Directory of Managed Care Organizations' (NDMCO's) database. NDMCO is a publicly available database that provides contact information and company profiles for MCOs. We attempted to sample from both large and small 
la) What is your position within the $\mathrm{MCO}$ ?

$\square \mathrm{CEO}$

$\square$ Pharmacy Director

$\square$ Benefits Manager

$\square$ Other

lb) Does your organization conduct its own formulary review, or is it contracted to another entity (such as a pharmaceutical benefit manager)? Conduct own formulary review. SKIP to 2

$\square$ Contract to another entity

$$
\text { If so, who? }
$$

Although you've contracted, is your organization still involved in the evaluation of dossiers?

Y Yes SKIP to 2

a No END INTERVIEW.

2) Are you personally involved in dossier reviews?

Yes SKIP to 3 .

No Ask for name, email, phone of the individual in the organization who is involved with the review.

\section{(END INTERVIEW)}

3) Which of the following activities describes your role in the formulary selection process? (CHECK ALL THAT APPLY)

$\square$ Prepare some or all of the drug monograph

Evaluate the submitted dossier

$\square$ Compile data from plan in therapeutic area for P\&T committee use

$\square$ Develop pharmacoeconomic models for P\&T use

$\square$ Present the staff recommendations

$\square$ Other (please specify)

4) In the last 6 months, what are the drug classes of dossiers that you, the respondent, have been personally involved in reviewing?

Cardiovascular

$\square$ Diabetes

$\square$ Pain

Schizophrenia

$\square$ Depression

$\square$ Lifestyle

$\square$ Other (please specify)

5) Approximately how many drugs have been reviewed over the last 6 months?

(If respondent has difficulty coming up with number, probe with the following formatted choices:)

None

a 1-3

a $4-6$

] $7-9$

a 10 or more

5a) Please estimate the number of those reviewed in the last 6 months that included dossiers from manufacturers?

(If respondent has difficulty coming up with number, probe with the following formatted choices:)

a None

a $1-3$

प $4-6$

] $7-9$

a 10 or more 5b) How many of these reviews have included an economic model that you considered adequate?

a $100 \%$

$75 \%$

$50 \%$

$\square 25 \%$

None

5c) How many of these included a budget impact model?

$\square 100 \%$

$\square 75 \%$

$\square 50 \%$

$25 \%$

None

5d) How many of these included an incremental cost-effectiveness or costbenefit ratio?

a $100 \%$

$\square 75 \%$

$\square 0 \%$

$\square 25 \%$

a None

6) How many times in the last 6 months has your staff developed an original economic model specific to a formulary decision?

(If respondent has difficulty coming up with number, probe with the following formatted choices:)

$\square$ None

a $1-3$

a $4-6$

$\square 7-9$

10 or more

If None, $\mathrm{GO}$ to $6 \mathrm{~A}$. If one or more, SKIP to 7 .

6a) If not in the last 6 months, when is the last time you developed your own model for formulary decision making?

$\square$ months-one year ago

More than one year ago

a Never

7) When thinking about the most recent dossier, did you modify the provided model for use with your own population?

$\square$ Yes If yes, what was the class of the drug that the last population modification was built for?

$\square$ No

8) When thinking about the most recent dossier, did you vary the assumptions of the model outside the bounds of the model that you have been given?

$\square$ Yes $\quad$ GO to $8 \mathrm{a}$

No SKIP to 9

8a) When thinking about the most recent dossier, which assumption made the most important difference?

a Pricing

Market share

Probabilities of events

$\square$ Quality-adjusted life-years

None of the above 
9) To what do you usually compare the drug under review?

Placebo? $\square$ Yes $\square$ No

At least one branded product? $\square$ Yes $\square$ No

If yes, how do you select the branded product?

Branded product with greatest market share within class

$\checkmark$ Cheapest branded product in class

$\square$ Branded product going generic soonest

D Other

10) Within your organization, who develops and evaluates economic models? (CHECK ALL THAT APPLY)

口 P\&T committee

$\checkmark$ Pharmacy Director

D Pharmacist

Statistician

D Pharmacoeconomist

10a) Approximately how many full-time employees (FTEs) have been involved in the development and review of dossiers within the last 6 months?

$\square<1$

$\square 1$

$\square 2$

$\square 3$

$\square 4$

5 or more

10b) Have you increased staff in the last 2 years to assist in dossier review? $\square$ Yes

$\square$ No 10c) Have you used outside experts or consultants to help you in your review?

$\square$ Yes

$\square$ No

11) Does the P\&T committee review the economic model?

$\square$ Yes

$\square$ No

12) How much time do you give the manufacturer to respond to a request for a dossier?

More than 4 months prior to product review

2-4 months prior to product review

1-2 months prior to product review

$\square$ Less than 1 month

13) How often do the manufacturers meet the timeline?

a $100 \%$ of the time

$\square 75 \%$

- $50 \%$

口 $25 \%$

$\square$ Never

14) What assurances are provided to manufacturers regarding the confidentiality of requested dossiers? (CHECK ALL THAT APPLY)

$\square$ Only staff involved in reviewing are allowed access to the dossier

$\square$ Only staff reviewing and P\&T committee are allowed access to the dossier

$\square$ The dossier will not be made public

No assurances are provided

$M C O=$ managed care organization; $P \& T=$ pharmacy $\&$ therapeutics.

companies, since organization size may affect the ways in which health plans evaluate and respond to dossier submissions. One hundred ninety-one pharmacy directors (or equivalent position) were contacted to complete the MCO telephone interview. A substantial number of telephone numbers were missing or inaccurate, 21 organizations refused to participate in the survey per company policy, and 64 pharmacy directors were unreachable. Nine (7 small, 2 large) MCO operators referred us directly to a PBM when we inquired about speaking to anyone involved in formulary decisions. There were no differences in company size between responders and nonresponders.

Pharmaceutical manufacturers. Members of the Pharmaceutical Research and Manufacturers of America (PhRMA) Foundation's Health Outcomes Committee were contacted to participate in the survey of pharmaceutical manufacturers. This committee is made up primarily of directors of health outcomes departments of pharmaceutical companies and consists of approximately 15 members, all of whom have experience with multiple dossiers developed in accordance with dossier guidelines. These respondents are likely representative of a very knowledgeable and involved group of pharmaceutical manufacturers.

\section{Results}

\section{Respondent Information}

MCOs. A total of 28 (18 small, 10 large) MCO representatives agreed to participate in the telephone interview. Four (3 small, 1 large) of the 28 respondents reported that their organizations contracted formulary decisions directly to a PBM, and these interviews were promptly ended. Three respondents (11\%) reported that their organizations did not use dossiers, and 1 individual was not personally involved in the review process, thus reducing our final sample to 20 (14 small, 6 large). Therefore, our final sample was approximately $10 \%$ of the original 191 MCO representatives that we attempted to contact.

Fifteen of those interviewed (75\%) held the position of pharmacy director, while the remaining 5 (25\%) had similar titles (chief pharmacy officer, pharmacy manager, or vice president of pharmacy). The most common responsibilities of the MCO respondent included evaluating the submitted dossier, compiling data from the health plan for P\&T committee use, and presenting staff recommendations at P\&T meetings.

Pharmaceutical manufacturers. Seven pharmaceutical manufacturer interviews were completed. Four respondents were directors of health economics and outcomes research, 


\section{TABLE 2 Pharmaceutical Manufacturer Survey}

1) What is your position within the company?

2) Are you personally involved in dossier preparation/submission?

$\square$ Yes SKIP to 3.

No Please provide name, email, phone of the individual in the company who is involved with the preparation and submission of dossiers.

\section{(END INTERVIEW)}

3) Which of the following activities describes your role in the dossier submission process? (CHECK ALL THAT APPLY)

$\square$ Request summary plan characteristics from MCO population

$\square$ Provide product description

$\square$ Prepare supporting clinical information

$\square$ Develop pharmacoeconomic models for P\&T use

$\square$ Other (please specify)

4) In the last 6 months, what are the drug classes of dossiers that you, the respondent, have been personally involved in preparing/submitting?

$\square$ Cardiovascular

$\square$ Diabetes

$\square$ Pain

Schizophrenia

$\square$ Depression

Lifestyle

Neurologic

Oncology

Respiratory

$\square$ Anti-infective

$\square$ Other (please specify)

5) Approximately how many drugs has your company submitted dossiers for over the last 6 months?

(If respondent has difficulty coming up with number, probe with the following formatted choices:)

None

a $1-3$

- 4-6

a $7-9$

a 10 or more

5a) How many of these dossier submissions included an economic model? - $100 \%$

$75 \%$

- $50 \%$

口 $25 \%$

None

5b) How many of these dossier submissions included a budget impact model? a $100 \%$

- $75 \%$

$\square 50 \%$

- $25 \%$

None

5c) How many of these dossier submissions included an incremental costeffectiveness or cost-benefit ratio?

$\square 100 \%$

- $75 \%$

口 $50 \%$

- $25 \%$

None 5d) Are these models submitted in their entirety and in a format that can be manipulated by the MCO (versus just an example of the model within text?)

$\square$ Yes

Do

6) When thinking about the most recent dossier, did you tailor the model to the requesting organization's population demographics?

$\square$ Yes If yes, what was the class of the drug that the last population modification was built for?

$\square$ No

7) Do you justify assumptions for the specific plan population?

$\square$ Yes

a No

8) When thinking about the most recent dossier submission, which assumption made the most important difference?

a Pricing

Market share

Probabilities of events

Quality-adjusted life-years

Combination of price and outcome

None of the above

9) Do you provide comparator information on:

Placebo? $\square$ Yes $\square$ No

At least one branded product? $\square$ Yes $\square$ No

If yes, how do you select the branded product?

$\square$ Branded product with greatest market share within class

Cheapest branded product in class

$\square$ Branded product going generic soonest

o Other

10) Does your company provide both on-label and off-label data?

$\square$ Yes

No

11) Do you build the models in house, or do you utilize consultants to assist in model-building?

In house

Consultants

Both

11a) Approximately how many full-time employees (FTEs) have been involved in the preparation and submission of dossiers within the last 6 months?

$\square<1$

$\square 1$

02

a 3

$\square 4$

5 or more

11b) Have you increased staff in the last 2 years to assist in dossier preparation/ submission?

$\square$ Yes

$\square$ No

11c) Have you used outside experts or consultants to help you in preparation/ submission?

$\square$ Yes

Do 
12) How much time are you given by the MCO to respond to a request for a dossier?

More than 4 months prior to product review

2-4 months prior to product review

1-2 months prior to product review

$\square$ Less than 1 month

13) Has the amount of notice improved over time?

$\square$ Yes

$\square$ No

14) How often does your company meet the timeline?

$100 \%$ of the time

$75 \%$

$\square 0 \%$

- $25 \%$

$\square$ Never

15) What assurances are provided to your company regarding the confidentiality of requested dossiers? (CHECK ALL THAT APPLY)

Only the MCO staff involved in reviewing are allowed access to the dossier

Only the MCO staff reviewing and P\&T committee are allowed access to the dossier

The dossier will not be made public

No assurances are provided
16) To what extent do you expect the new guidelines to change the submission process?

$\square$ Improve

Worsen

No change

17) Have you begun adapting the dossier for a Medicare population?

$\square$ Yes

a No

18) Has your company submitted dossiers to Medicaid?

$\square$ Yes (GO to 18a)

No (SKIP to 19)

18a) Do you believe the dossier has been helpful in informing discussion/ negotiation with the state?

$\square$ Yes

$\square$ No

18b) Do you anticipate a similar process with the Prescription Drug Plans? $\square$ Yes

$\square$ No

19) Do you expect that Prescription Drug Plans will begin requesting dossiers for their formulary reviews?

$\square$ Yes

№

$\mathrm{MCO}=$ managed care organization; $P \& T=$ pharmacy $\&$ therapeutics.

2 were senior directors of global health outcomes, and 1 was a global project leader/MCO liaison. All 7 respondents reported that their main involvement in the dossiers involved developing pharmacoeconomic models and collating and reviewing all sections of the document.

\section{Key Interview Topics}

\section{Drug Product Reviews}

MCOs. Awareness of the AMCP Format was high, with 21 of the 24 (87.5\%) MCO personnel initially contacted having reviewed dossiers within their organizations. However, on average, respondents indicated that only $40 \%$ of all drugs reviewed by MCOs included dossiers from the manufacturer. Table 3 shows that, across all respondents, the drug classes of dossiers most commonly submitted and reviewed in the 6 months before the interview were (1) cardiovascular, (2) lifestyle (including erectile dysfunction, incontinence, dermatology, irritable bowel syndrome), (3) pain, and (4) antibiotics.

On average, 26.5 individual drugs were reviewed over the 6 months before the interview (small $\mathrm{MCO}=23$ drugs; large $\mathrm{MCO}=36$ ). There appeared to be 2 common approaches to formulary reviews at the P\&T level. Individual drug candidates were either specifically evaluated at the time of request (most likely at product launch), or the drug was evaluated as part of a general therapeutic class review scheduled to incorporate the new U.S. Food and Drug Administration (FDA)-approved agent. This variation in $\mathrm{P} \& \mathrm{~T}$ committee meetings to review drugs may explain the large variation in the number of drugs reviewed, with 7 (35\%) respondents reporting less than a dozen products reviewed over the past 6 months, and 4 (20\%) reporting more than 50 products. Our results were similar to those found by Sullivan, whose discussions also revealed variability in the frequency of P\&T committee meetings. ${ }^{9}$

Pharmaceutical manufacturers. Pharmaceutical industry respondents reported that they submitted dossiers to MCOs for approximately 3.9 (range 2-6) individual drugs in the 6 months before the survey interview.

\section{Drug Comparisons}

MCOs. For drug evaluation at the P\&T level, we found that drugs were compared with a variety of products, with 11 respondents reporting comparisons with a placebo, and all respondents reporting a comparison with at least 1 other branded product. For new drugs in a new class, comparisons were made with a placebo, since few companies conduct head-to-head studies before product launch. ${ }^{11}$ Products in the same pharmacologic class or therapeutic class were always compared with the other branded products, with the majority of comparisons between 
Opinions Regarding the Academy of Managed Care Pharmacy Dossier Submission Guidelines:

Results of a Small Survey of Managed Care Organizations and Pharmaceutical Manufacturers

TABLE 3 Drug Classes of Dossiers Submitted/Reviewed in the 6 Months Prior to Interview

\begin{tabular}{|c|c|c|c|c|}
\hline Drug Class & $\begin{array}{l}\text { Small MCO } \\
\quad(n=14)\end{array}$ & $\begin{array}{c}\text { Large MCO } \\
\quad(n=6)\end{array}$ & $\begin{array}{c}\text { Pharma } \\
(n=7)\end{array}$ & $\begin{array}{c}\text { Total } \\
(\mathrm{n}=27)\end{array}$ \\
\hline Cardiovascular & 11 & 5 & 2 & 18 \\
\hline $\begin{array}{l}\text { Lifestyle (includes erectile dysfunction, incontinence, } \\
\text { dermatology, irritable bowel syndrome) }\end{array}$ & 8 & 6 & 4 & 18 \\
\hline Pain (includes RA and migraine) & 7 & 5 & 0 & 12 \\
\hline Diabetes & 2 & 2 & 0 & 4 \\
\hline Schizophrenia & 3 & 2 & 0 & 5 \\
\hline Depression & 4 & 1 & 0 & 5 \\
\hline Hormone replacement & 2 & 1 & 0 & 3 \\
\hline Antibiotics/anti-infective/antivirals & 7 & 3 & 6 & 16 \\
\hline Respiratory/asthma & 4 & 1 & 3 & 8 \\
\hline$\overline{\mathrm{ADHD}}$ & 4 & 0 & 0 & 4 \\
\hline Alzheimer's & 4 & 0 & 0 & 4 \\
\hline Oncology & 0 & 0 & 1 & 1 \\
\hline Other & 18 & 3 & 5 & 26 \\
\hline Totals & 74 & 29 & 21 & 124 \\
\hline
\end{tabular}

$A D H D=$ attention-deficit/hyperactivity disorder; $M C O=$ managed care organization; $R A=$ rheumatoid arthritis .

drugs currently on the formulary.

Most MCO respondents commented at the end of the interview that their primary focus was on clinical efficacy and safety when they made comparisons. If products were equal on these measures, the decision to adopt the medication was then based on financial considerations. Others indicated that formulary decisions rely heavily on rebate options known commonly as the "bid grid," where adding another drug to a therapeutic class decreases the existing rebate structure. The "bid grid" is a tool to determine how the existing rebate structure for competitors' products will change if the drug being considered is added to the formulary in that particular therapeutic class.

Our findings are similar to results from a focus group study by Delate et al. involving P\&T committee members. ${ }^{13}$ Participants in the Delate study ranked the importance of factors for making drug coverage decisions using a 5-point scale ( $1=$ not important, $5=$ very important). Efficacy was ranked as the most important factor (mean=4.9), followed by cost-effectiveness (4.4), cost (4.0), and safety (4.0). ${ }^{13}$

Pharmaceutical manufacturers. Pharmaceutical industry respondents reinforced the MCO results regarding drug comparisons. Five of the 7 companies responding indicated that their dossiers included comparator information with a placebo. All respondents reported providing comparisons with at least 1 branded product, which typically involved the product with the greatest market share within its class. Two of the 7 respondents (28.5\%) reported that their companies provided information on all available comparators.

\section{Development and Review of Economic Models}

MCOs. On average, respondents reported that $53.5 \%$ of dossiers received included budget-impact models and 39.3\% included cost-effectiveness analyses (CEAs) or cost-benefit analyses (CBAs). A recent study by Spooner et al. ${ }^{14}$ found that pharmacoeconomic models were included in $68 \%$ of the dossiers received. Table 4 shows that, of the dossiers with economic models, respondents from the current study believed that nearly half $(46.2 \%)$, on average, contained adequate economic models.

There was a notable difference between small and large MCO respondents, with small plans reporting that $59.5 \%$ of dossiers contained an adequate economic model, and large plans reporting an adequate model only $9 \%$ of the time. The difference between large and small MCOs for the percentage of dossiers containing an adequate economic model might be a function of the level of expertise in evaluating such models. If smaller health plans are less familiar with economic models or lack the staff to assist in evaluation, they may be more likely to deem a model adequate, whereas a larger plan with more staff and/or experience may not regard it as such. Alternatively, the needs of smaller MCOs might be more modest in dossier reviews than might those of the larger organizations. The capacity of MCOs to adequately interpret and use cost-effectiveness information is unknown. Smaller organizations might not have the resources available for staff training or might prefer contracting out to consultants, such as academic centers.

Fifteen (75\%) MCO respondents reported being involved in some capacity with developing or evaluating the economic 
Opinions Regarding the Academy of Managed Care Pharmacy Dossier Submission Guidelines:

Results of a Small Survey of Managed Care Organizations and Pharmaceutical Manufacturers

TABLE 4 Summary of Responses on Economic Models

\begin{tabular}{|c|c|c|c|}
\hline & $\begin{array}{c}\text { Small MCO } \\
(n=14)\end{array}$ & $\begin{array}{l}\text { Large MCO } \\
\quad(n=6)\end{array}$ & $\begin{array}{c}\text { All MCO } \\
(\mathrm{n}=20)\end{array}$ \\
\hline \multicolumn{4}{|l|}{ Over past 6 months } \\
\hline Mean number [SD] of drugs reviewed with dossiers & $5.5[4.3]$ & $5.0[3.4]$ & $5.4[4.0]$ \\
\hline Mean percent [SD] with adequate model & $59.5 \%[33.4 \%]$ & $9.0 \%[12.5 \%]$ & $46.2 \%[36.9 \%]$ \\
\hline Mean percent $[S D]$ with BI model & $58.3 \%[33.7 \%]$ & $40.0 \%[41.8 \%]$ & $53.5 \%[35.7 \%]$ \\
\hline Mean percent [SD] with CEA or CBA & $44.6 \%[35.3 \%]$ & $24.2 \%[42.6 \%]$ & $39.3 \%[37.3 \%]$ \\
\hline Mean number [SD] developing original model & $9.0[19.9]$ & $4.6[4.7]$ & $7.8[17.2]$ \\
\hline \multicolumn{4}{|l|}{ Most recent dossier } \\
\hline No. of MCOs that modified the model & 10 & 3 & 13 \\
\hline No. of MCOs that varied assumptions & 5 & 1 & 6 \\
\hline
\end{tabular}

models, while 6 reported that they had a pharmacoeconomist on staff to assist in dossier reviews. In the 6 months before the interview, approximately 8 (40\%) MCOs, on average, reported that they had developed original economic models specific to formulary decisions. It is difficult to assess the degree of sophistication involved in these models from interview responses alone. However, on the basis of additional comments from respondents, it appears that the complexity varied drastically from simple utilization or rebate models to more complex costeffectiveness models.

Thirteen of 20 (65\%) MCO respondents reported that they modified the provided model with their own population statistics, as many reported that manufacturers do not make models directly applicable to their health plan population (Table 4). Many commented that if the manufacturers tailored models to reflect situations specific to individual MCOs, it would make the models much more beneficial. These findings corroborated those of Sullivan et al., in which respondents urged transparency in economic models so P\&T committees could easily input their plan demographics into the model. ${ }^{9}$

Similarly, about one third ( 6 of 20) of respondents indicated that they commonly varied the assumptions of models that permitted such testing. The relatively small proportion who conducted these analyses may believe that small changes in an economic model will not have a major impact. Of those who did vary assumptions, they made the key drivers of the models the price of the products and the probability of events associated with treatment. None suggested that assumptions regarding quality-adjusted life-years (QALYs) were of critical importance to the model outcome.

Many MCO respondents complained during their interviews that models provided by drug companies were unnecessarily awkward and difficult to manipulate. Additionally, most commented during the interview that they would rather see simple and easy-to-follow models relevant to specific decisions. Another reason to provide less complicated models is that P\&T committees comprise physicians and pharmacists who have not been trained to evaluate cost-effectiveness models. Most MCOs reported that economic models were commonly presented to the committee in a summary review format, with technical aspects omitted. Similarly, roundtable participants in the Sullivan study commented that economic models should be presented in a format comprehensible by P\&T committee members. ${ }^{9}$ Specifically, they recommended emphasizing clinically meaningful findings over statistically significant results.

Pharmaceutical manufacturers. The perspectives of the pharmaceutical manufacturers interviewed varied dramatically from the MCO respondents with regard to the inclusion of economic models. Five of the respondents indicated that their companies always included an economic model in the submitted dossiers. Of the remaining 2 respondents, 1 indicated that $85 \%$ of their dossiers included models, and the other reported that $50 \%$ of their dossiers included CEA models.

Only 1 of the 7 pharmaceutical manufacturer respondents reported tailoring the model to the requesting health plan's population. The majority (70\%) of MCOs reported modifying the model in-house with their own population. Most pharmaceutical respondents reported basing models on national prevalence rates, while 1 individual was under the impression that MCOs preferred to not provide plan-specific information. On this subject specifically, there appears to be a clear disconnect between MCOs and pharmaceutical 


\section{Opinions Regarding the Academy of Managed Care Pharmacy Dossier Submission Guidelines:}

Results of a Small Survey of Managed Care Organizations and Pharmaceutical Manufacturers

manufacturers. Better communication from the MCOs regarding what is expected or desired will enable manufacturers to provide more specific and, hence, more valuable models. This was demonstrated in the Watkins study, in which effective communication between manufacturer and payer resulted in the decision to include exenatide on the formulary. ${ }^{8}$

Only 3 pharmaceutical manufacturers' respondents varied the assumptions of the provided model. Assumptions that made the most difference according to pharmaceutical manufacturers were a combination of pricing and outcome (i.e., probabilities of events or QALYs).

\section{Organizational Burden}

The additional burden on staff and financial resources continues to be a common complaint of the AMCP dossier format for both MCOs and pharmaceutical firms. ${ }^{5}$

MCOs. In this sample, the majority ( 16 of 20) reported having a pharmacy director involved in developing and evaluating economic models, while 13 of 20 reported P\&T committee involvement. The average number of full-time equivalent (FTE) staff members involved in the dossiers in the past 6 months was 5.2. Only 5 of the MCOs reported hiring additional in-house staff within the past 2 years to assist in the dossier review, although 5 of 20 individuals (25\%) mentioned, in open commentary, that more help was desired. Fourteen (70\%) of the MCOs interviewed used outside experts to assist in dossier review in the previous 6 months. Fifty percent of the large companies indicated that they used outside consultants, while $71 \%$ of the small companies enlisted the aid of outside sources.

Pharmaceutical manufacturers. All 7 pharmaceutical company respondents reported building models both in-house as well as with the aid of outside consultants. An average of 1.43 FTEs were involved in developing and reviewing dossiers within the past 6 months. Only 1 of the pharmaceutical manufacturer respondents in our sample reported hiring additional company employees within the past 2 years to assist in the dossier submission process.

\section{Dossier Timelines}

MCOs. MCO respondents reported that the timelines related to requests for dossiers ranged anywhere from no deadline ( 3 of 20 respondents) to 6 months (1 of 20 respondents) before product review. Four of 20 respondents (20\%) were not aware of an imposed deadline because they were not personally involved in dossier requests. On average, the MCO respondents who request dossiers reported that manufacturers met the MCOimposed deadlines approximately $83 \%$ of the time.

Pharmaceutical manufacturers. Five of the 7 pharmaceutical company respondents were familiar with the timelines associated with requests. Similar to the MCOs, these pharmaceutical manufacturers reported that the deadlines imposed on dossier requests ranged from no deadline to 6 months before product review. Pharmaceutical manufacturers reported meeting the deadline about $95 \%$ of the time, which was slightly higher than the figures $(84 \%)$ reported by MCOs. One pharmaceutical manufacturer respondent commented that the company proactively develops the principal components of the dossiers before product launch (as opposed to waiting for a request) and is therefore more likely to meet timelines.

\section{Confidentiality}

Dossier confidentiality is a great concern for pharmaceutical manufacturers, as they are often fearful their proprietary information will be made public. ${ }^{5}$

MCOs. Half (10 of 20) of the MCOs reported giving verbal assurances to the manufacturers regarding confidentiality, while the other half reported that no assurances were made.

Pharmaceutical manufacturers. Only 5 of the 7 respondents (71\%) were familiar with the confidentiality issues associated with dossier submission. The perspectives of these 5 manufacturers were fairly consistent with the MCO reports on confidentiality. One of the pharmaceutical manufacturers reported that the company requires MCOs to sign a legal confidentiality agreement, but that was not the norm. Four pharmaceutical company representatives reported that they were given verbal assurances by the MCOs that the dossier would not be made public, and 1 reported that no assurances were made. Four of the 5 firms commented on the need for more clearly documented confidentiality guidelines.

\section{Overall Value to Formulary Decisions}

MCOs. MCO respondents held various opinions regarding the overall value of the AMCP dossier format. The majority of these opinions were expressed as open-ended comments at the end of the structured survey questions. Some have made the formal decision to include dossiers in their decision-making process, while others do not use them because they fail to see the value they provide, primarily because of perceived bias on the part of the pharmaceutical manufacturers.

In a recent article by Fullerton and Atherly, ${ }^{7}$ Regence BlueShield stated that, between January 1998 and June 2000, drugs with useful economic models were approved $75 \%$ of the time versus $54 \%$ for all drugs reviewed in that time period. Some of the major criticisms (in order of frequency) involve the applicability, length, complexity, and potential bias in models developed by pharmaceutical manufacturers as a key component of the dossier format. Many MCO respondents commented that the models were created to produce desired results, and their construction should be scrutinized. Other respondents reported that because the manufacturers have clearly biased views, their organizations do not give the economic model portion of the dossier reviews much weight in the formulary decision process. On this basis, one may assume that manufacturers with such information may hesitate to put much effort into models if they 
believe they are likely to be overlooked or disregarded.

Pharmaceutical manufacturers. In general, pharmaceutical manufacturers felt that the AMCP Format provided an opportunity to convey the value of a product, including more latitude for economic analyses and arguments. Nearly all (95\%) respondents in Olson's survey of industry pharmacoeconomists reported that an economic model played a role in improving product positioning on formularies at least once in their experience. ${ }^{10}$ The results from the study by Spooner et al. showed no relationship between dossier receipt and placement on the formulary. ${ }^{14}$ In fact, products that included a dossier submission were less likely ( $0 \%$ ) to be placed on the formulary at the second (preferred) copayment tier compared with those without a dossier (33\%).

\section{Expectations for the Future}

Version 2.1 of the AMCP Format (which became available in April 2005) included changes encouraging clarity in presenting model results and a need to clearly differentiate between cost-effectiveness and budget-impact models. ${ }^{15}$ Three of the pharmaceutical manufacturers interviewed believe the new AMCP guidelines will improve the submission process, while the other 3 expected that the guidelines will not affect the current process. Since the Centers for Medicare and Medicaid Services have publicly stated their intention to develop a framework for formulary management based on existing national standards and guidelines (such as those established by AMCP), ${ }^{16}$ we asked participants about their expectations in this area. Five of the 7 respondents (71\%) reported having already adapted the dossier for Medicaid, and 3 of these (60\%) reported that the dossiers had been helpful in informing discussion and negotiation with Medicaid. All manufacturers interviewed believed that prescription drug plans (Medicare Advantage and PDPs) would begin requesting dossiers for their formulary reviews in the near future.

\section{Discussion}

It was our intention at the beginning of this project to determine the extent to which the AMCP Format was being used within MCOs and drug companies and what impact the dossiers might have on formulary decisions. The data gathered provide important descriptive information on the similarities and differences in perceptions of the respondents who represented the 2 organization types. In addition to giving specific survey responses to structured questions, many interviewees provided comments regarding their overall perspective of the AMCP dossier process.

Overall, findings for this study suggest that awareness of the AMCP Format is high among persons in MCOs with drug formulary decision-making responsibility and among employees of pharmaceutical manufacturers involved in preparing product dossiers, but it is necessary to align objectives between the
2 organization types. Conceptually, proving the value of a drug beyond what the FDA requires is a reasonable request; this was agreed on by almost all respondents in one form or another. However, less than half of all drugs reviewed had a dossier. In contrast to the MCO respondents, pharmaceutical manufacturer respondents appear to have a more positive outlook on the role of the AMCP Format in effectively communicating the value of a new drug product. Further steps need to be taken to improve acceptance and integration of the AMCP Format into the formulary decision-making process.

The different perceptions of the manufacturers and MCOs seem most acute in the use of the Format's economic model. Although safety and efficacy information is more widely accepted by MCOs, many of them have attitudes of distrust and skepticism with the economic analysis portion. It appears that there are 2 different pharmaceutical company perspectives1 that provides a modifiable model for MCOs to adjust as they see fit, and 1 that provides all the answers with a very specific, tailored model. The latter may reflect the belief that the MCOs will not adjust model parameters or might not have staff capable of developing plan-specific data and of appropriately altering the model parameters.

Our evaluation supports past research that suggests that although many pharmaceutical companies submit dossiers to P\&T committees, very few follow the AMCP Format rigorously; most often omit the economic model. ${ }^{9,14}$ While Olson found that MCOs sought model simplicity, ability to customize the model, and transparency, ${ }^{10}$ it appears that submissions addressed in our research are still lacking in these elements, at least in the perception of the MCOs surveyed. Just more than half of the pharmaceutical company respondents reported including the entire model in the dossier, while others included only a summary but offered the model in its entirety on request.

The usefulness of the economic model becomes a key point as Medicaid pharmacy managers gain more experience with their use in formulary decision making because their interests may be different from those of large MCOs. Most important, Medicaid agencies may have even more acute staff capacity constraints that affect their ability to analyze a model in detail. Models for Medicaid agencies may need to focus on special populations, although this may be a rather steep challenge for pharmaceutical companies because of limited data for populating key elements of the model.

On the basis of our findings, we make the following recommendations:

1. MCOs and pharmaceutical manufacturers engage in continuous communication. MCOs must take a proactive role in initiating dossier requests from pharmaceutical manufacturers. Additionally, MCOs must be willing to provide feedback regarding the perceived shortcomings of the dossier submissions to permit pharmaceutical manufacturers to better meet MCOs' expectations. 
2. MCOs need to devote additional resources to evaluating drug dossiers. MCOs need to employ reviewers who have the capability to discern potential model biases as well as the appropriateness of the model in their member populations. Economic models could provide insight into other business processes and policies, but it's not clear that MCOs have the necessary staff capacity to maximize these opportunities.

3. Pharmaceutical manufacturers need to adopt a perspective of transparency, consistency, and flexibility in their modeling efforts. The principal purpose of the dossier is to determine the drug's place in treatment, and manufacturers need to consider the dossier as part of a broader strategy toward appropriate therapeutic decision making in general.

4. Because many MCOs now forbid sharing the information discussed in our interview, AMCP needs to promote an anonymous reporting system for both MCOs and pharmaceutical manufacturers to discuss the usefulness of the Format in their efforts to continue to refine their development and evaluation processes.

Such actions would allow the AMCP Format to function as intended-providing increased access to information about new drugs, facilitating the formulary decision-making process, and generating higher levels of confidence in the decisions made.

\section{Limitations}

The first and main limitation of this study was the small sample size, which makes it difficult to generalize our findings. Nevertheless, our data provide information on how the guidelines are being used and integrated, which is an area that needs additional research.-6 Second, because our pharmaceutical manufacturer respondents were chosen from the PhRMA Foundation's Health Outcomes Committee and were therefore very knowledgeable and involved, these respondents may not reflect pharmaceutical manufacturers as a whole. This fact may also make it more difficult to compare their answers with those of MCO respondents, who were selected at random. Third, we did not assess the perspective of the PBMs, which would have provided additional insight into the use of the AMCP Format in formulary decisions in the United States.

Fourth, it is possible that individuals who participated in the interview were "gaming" their answers or were not entirely forthcoming about their practices. We attempted to minimize this possibility by developing questions that would require the individual to have prior knowledge of terms and concepts to respond appropriately. A fifth limitation of this study design is that it was retrospective in nature and relied on the respondents' recall.

Sixth, selection bias must be considered, since those who volunteered their time to participate in the interview process could have been more likely to praise or criticize the dossier process. We anticipate that the ability to gather future survey information on this topic will become more difficult since many MCOs and PBMs now have policies and procedures that prohibit sharing this type of information. Therefore, our data are valuable, especially if future studies of this nature are not well received.

\section{Conclusions}

Findings from our current research assess perceptions regarding the AMCP Format and give us insight into possible process improvements. As evidenced by open-ended comments from survey respondents, the current research reinforces the need for increased staffing and training, improved collaboration with individuals and companies experienced in pharmacoeconomic modeling, and improvements in model consistency, transparency, and flexibility. Additionally, our findings suggest the need for greater communication between model developers and users so they have similar expectations.

\section{Authors}

MICHAEL B. NICHOL, PhD, is an associate professor, TARA K. KNIGHT, $\mathrm{PhD}$, is a research associate, and JOSHUA EPSTEIN, MA, is a research assistant, Department of Pharmaceutical Economics and Policy, School of Pharmacy, University of Southern California, Los Angeles; DENNIS H. HONDA, PharmD, is director, U.S. Regional Medical \& Research Specialist, Diabetes \& Metabolism Group, and ROMA TRETIAK, MHA, is senior director/team leader, Customer Outcomes Research, Pfizer Global Pharmaceutical Operations, New York, New York.

AUTHOR CORRESPONDENCE: Michael B. Nichol, PhD, Associate Professor, Department of Pharmaceutical Economics and Policy, School of Pharmacy, University of Southern California, 1540 E. Alcazar St., CHP 140, Los Angeles, CA 90033. Tel: (323) 442-1464; Fax: (323) 442-1462; E-mail:mnichol@usc.edu

\section{DISCLOSURES}

Funding for this study was provided by an unrestricted research grant from Pfizer, Inc., and was obtained by author Michael B. Nichol. Nichol is a consultant to Pfizer Inc., and authors Dennis H. Honda and Roma Tretiak are employed by Pfizer, Inc. The coauthors disclose no potential bias or conflict of interest relating to this article. Nichol served as principal author of the study. Study concept and design were contributed by Nichol, Honda, and Tretiak, with input from author Tara K. Knight. Data collection was the work of Knight and author Joshua Epstein; data interpretation was primarily the work of Nichol, with a substantial contribution from Knight and Epstein. Writing of the manuscript was primarily the work of Nichol, with a substantial contribution from Knight and Epstein; its revision was the work of Nichol, Knight, Honda, and Tretiak.

\section{REFERENCES}

1. Suh D, Okpara IR, Agnese WB, Toscani M. Application of pharmocoeconomics to formulary decision making in managed care organizations. Am J Manag Care. 2002;8(2):161-69.

2. Mather D, Sullivan SD, Augenstein D, Fullerton DS, Atherly D. Incorporating clinical outcomes and economic consequences into drug formulary decisions: a practical approach. Am J Manag Care. 1999;5(3):277-85. 


\section{Opinions Regarding the Academy of Managed Care Pharmacy Dossier Submission Guidelines: Results of a Small Survey of Managed Care Organizations and Pharmaceutical Manufacturers}

3. Fullerton D, Atherly D, Sullivan SD. Showing outcomes and proving value brings success. Manag Care Interface. 2001;14(6):63-65.

4. Atherly DE. Incorporating clinical outcomes and economic consequences into drug formulary decisions: evaluation of thirty months of experience. Value Health. 2001;4(2):52.

5. Neumann P. Evidence-based and value-based formulary guidelines. Health Aff. 2004;23(1):124-34.

6. Robinson A. AMCP's Format for Formulary Submissions: an evolving standard-results of two recent surveys. Presentation at: the Fifteenth Annual Meeting of the Academy of Managed Care Pharmacy; April 9-12, 2003; Minneapolis, MN.

7. Fullerton P, Atherly DS. Formulary development at Regence BlueShielda formula for success. Value Health. 2002;5(4):297-300.

8. Watkins JB, Minshall ME, Sullivan SD. Application of economic analyses in U.S. managed care formulary decisions: a private payer's experience. J Manag Care Pharm. 2006;12(9):726-35. Available at: http://www.amcp.org/data/ jmcp/726-735.pdf. Accessed April 17, 2007.

9. Sullivan P, Valuck R, Brixner DI, Armstrong EP. Managed care's response to a pharmacoeconomic model of serotonin reuptake inhibitors. Pharm Ther. 2005;30(3):178-82

10. Olson B, Armstrong EP, Grizzle AJ, Nichter MA. Industry's perception of presenting pharmacoeconomic models to managed care organizations. J Manag Care Pharm. 2003;9(2):159-67. Available at: http://www.amcp.org/ data/jmcp/Formulary\%20Management-159-167.pdf. Accessed April 17, 2007.
11. DiMasi JA, Caglarcan E, Wood-Armany M. Emerging role of pharmacoeconomics in the research and development decision-making process. Pharmacoeconomics. 2001;19(7):753-66.

12. Armstrong E, Abarca J, Grizzle AJ. The role of pharmacoeconomic information from the pharmaceutical perspective. Drug Benefit Trends. 2001;13(3):39-45.

13. Delate T, Ernst FR, Coons SJ. The role of health-related quality-of-life data in pharmacy benefit decisions. Pharm Ther. 2002;27(1):24,30-32.

14. Spooner J, Gandhi PK, Connelly SB. AMCP Format dossier requests: manufacturer response and formulary implications for one large health plan. J Manag Care Pharm. 2007;13(1):37-43. Available at: http://www.amcp.org/data/ jmcp/37-43.pdf. Accessed April 17, 2007.

15. Academy of Managed Care Pharmacy. A format for submission of clinical and economic data in support of formulary consideration by health care systems in the United States. The AMCP Format for Formulary Submissions, Version 2.1. April 2005. Available at: http://www.fmcpnet.org/index. cfm?pl=ADEE1897. Accessed April 17, 2007.

16. Centers for Medicare \& Medicaid Services. Medicare Modernization Act final guidelines-formularies. CMS strategy for affordable access to comprehensive drug coverage. Guidelines for reviewing prescription drug plan formularies and procedures. Available at: http://www.cms.hhs.gov/PrescriptionDrug CovContra/Downloads/FormularyGuidance.pdf. Accessed November 21, 2006 